\title{
The Role of mTOR Inhibitors for the Treatment of B-Cell Lymphomas
}

\author{
Pinelopi Argyriou, ${ }^{1}$ Panagiota Economopoulou, ${ }^{2}$ and Sotirios Papageorgiou ${ }^{2,3}$ \\ ${ }^{1}$ Department of Pathology, "Evangelismos" General Hospital of Athens, Athens, Greece \\ ${ }^{2}$ Haematology Unit, Second Department of Internal Medicine-Propaedeutic, University General Hospital "Attikon", Greece \\ ${ }^{3}$ Department of Clinical Haematology, Royal Free Hospital, London NW3 5QG, UK
}

Correspondence should be addressed to Sotirios Papageorgiou, sotirispapageorgiou@hotmail.com

Received 15 February 2011; Accepted 7 April 2011

Academic Editor: Kevin D. Bunting

Copyright (C) 2012 Pinelopi Argyriou et al. This is an open access article distributed under the Creative Commons Attribution License, which permits unrestricted use, distribution, and reproduction in any medium, provided the original work is properly cited.

Despite the fact that the majority of lymphomas initially respond to treatment, many patients relapse and die from disease that is refractory to current regimens. The need for new treatment strategies in lymphomas has led to the investigation and evaluation of novel agents that target cellular pathways. The mammalian target of rapamycin (mTOR) is a representative pathway that may be implicated in lymphomagenesis. Rapamycin and especially its derivatives (temsirolimus, everolimus, and deforolimus) represent the first described mTOR inhibitors. These agents have shown promising results in the treatment of lymphoid malignancies. On the other hand, new ATP-competitive mTOR inhibitors that provoke a broader inhibition of mTOR activity are in early stages of clinical development. The purpose of this paper is to summarize the existing knowledge about mTOR inhibitors and their use in the treatment of B-cell lymphomas. Relevant issues regarding mTOR biology in general as well as in B-cell lymphoid neoplasms are also discussed in short.

\section{Introduction}

Current approaches in treating lymphoid malignancies have focused on the development of therapeutic regimens that selectively target dysregulated signal transduction pathways in neoplastic cells. Among aberrantly activated signaling cascades that are implicated in the pathogenesis of lymphomas is the mammalian target of rapamycin (mTOR) pathway, which is involved in many vital cellular processes [1]. Rapamycin and its analogs (rapalogs) comprise the classical mTOR inhibitors. A number of completed as well as other ongoing preclinical and clinical trials have tested these drugs in lymphomas, either as monotherapy or in combination with established chemotherapy [1]. Moreover, other anti-mTOR molecules, such as specific active-site TOR inhibitors (asTORi), with better pharmacological profiles are candidate drugs to be tested in clinical trials against lymphoid malignancies [2].

Herein we aim to review the results of trials with mTOR inhibitors in B-cell lymphomas. Firstly, the mTOR signaling network as well as possible aetiologic factors of aberrant activation of the mTORC1 signaling cascade in B-cell lymphoid malignancies are discussed in short.

\section{2. mTOR Signaling Network}

Rapamycin (also known as sirolimus or Rapamune, Wyeth) is the first described mTOR inhibitor [3]. This drug, originally developed as an antifungal agent, was soon found to have immunosuppressive and antineoplasmatic actions [4]. Systemic efforts to decipher the molecular mechanisms of these actions led to the isolation of the mTOR protein and the identification of two multimolecular complexes that are formed by mTOR, namely, the mTOR complex 1 (mTORC1) and 2 (mTORC2) $[4,5]$. mTOR is the mammalian ortholog of a yeast serine-threonine kinase called target of rapamycin (TOR) [6]. Except for mTOR itself and the proteins mLST8/ G $\beta$ L [mammalian LST8 (lethal with SEC13 protein 8), also known as $G$ protein beta subunit-like] and DEPTOR, which are common in both mTORC1 and mTORC2, several different constitutional proteins associate to form the two mTOR complexes $[7,8]$. These multipeptidic structures are 
situated inside a signaling network, the mTOR network, characterized by many feedback loops and crosslinks among its various components [9].

Activity of mTORC1 is regulated by multiple molecular pathways that conduct input generated by growth factors, hormones, cytokines, amino acids, energy, stress- and oxygen-related signals [10-13]. Among these cascades are the PI3K/Akt (Phosphoinositide 3-kinase/Akt) and Raf/MEK/ ERK (Raf/MEK/extracellular signal-regulated kinase) pathways, which are commonly activated in cancer and may cooperate in malignant transformation $[9,12]$. Both pathways trigger the activity of mTORC1 through downregulation of the inhibitory effect of the TSC1-TSC2 (tuberous sclerosis complex 1-tuberous sclerosis complex 2) complex on Rheb (Ras homolog enriched in brain) protein $[10,12]$. Akt kinase affects mTOR by way of two mechanisms. First, it lies upstream of mTORC1 and controls its activation. Second, Akt lies downstream of mTORC2 and depends on the latter as well as on PDK1 (pyruvate dehydrogenase kinase, isozyme 1) for full activation $[7,14]$.

Regulation of the two mTOR complexes bears some resemblance. For example, similarly to mTORC1, mTORC2 may also be activated by growth factors, hormones and amino acids, and this upregulation may be PI3K mediated [7, 15, 16]. In contrast, the TSC1-TSC2 complex, which suppresses mTORC1 activity, may promote mTORC2 signaling [10]. mTORC2 regulates Akt, SGK1(serum- and glucocorticoidinduced protein kinase 1), and PKC $\alpha$ (protein kinase C, alpha) phosphorylation and controls organization of actin cytoskeleton as well as cell size, cell cycle progression, proliferation, and survival $[7,15,16]$. The best characterized targets of mTORC1 are the S6 kinases [S6K1 (also known as p70S6) and S6K2] and the eukaryotic initiating factor-4e (eIF4e) binding proteins 1 and 2 (4E-BP1 and 4E-BP2) [911]. Upon activation, mTORC1 triggers vital anabolic processes such as ribosome biogenesis, cap-dependent transla tion, uptake of nutrients including glucose and amino acids, biosynthesis of amino acids, proteins, and lipids as well as (adenosine triphosphate) ATP sensing. Moreover, gene transcription, cell growth, cell cycle progression, proliferation, and survival are induced $[4-7,9,17]$. In addition, active mTORC1 downregulates macroautophagy and other catabolic processes such as fatty acid oxidation and protein degradation, while, in contrast, it stimulates aerobic glycolysis $[4,5,17,18]$.

Dysregulated activation of the mTORC1 pathway has been associated with tumor biology. Aberrant mTORC1 signaling disrupts homeostatic cell balance and contributes to uncontrolled proliferation and cell growth, survival, as well as angiogenesis and metastasis [9]. The same malignancyinducing processes may be also promoted by abnormally elevated mTORC2 signaling [16, 19-21].

\section{Aberrant mTORC1 Pathway Activation in B-Cell Lymphomas}

Several lines of evidence indicate that aberrant activation of the mTORC1 pathway is common in both Hodgkin (HLs) and many types of B-cell non-Hodgkin lymphomas (NHLs) (Table 1) [22-25, 27, 28, 30-33, 40-42, 46-49]. However, the cause of this upregulation is currently poorly defined. Molecular events that affect signaling pathways related to mTORC1 complex modulation may presumably have an impact on the mTORC1 pathway itself [9]. Notably, the PI3K/ Akt pathway, which is abnormally activated in many types of B-cell lymphomas, seems to participate in mTORC1 upregulation at least in a subset of these entities [22, 25, 27-29, 3139, 41, 43-45, 47-49] (Table 1).

Several possible mechanisms of PI3K/Akt pathway activation in mature malignant lymphoid B cells have been described. These include (a) overexpression of membrane receptors which may be mutation related, and/or stimulation by their ligands by autocrine/paracrine secretion [23, 3639, 41, 50], (b) aberrant tyrosine kinase (TK) activity [51], (c) constitution of oncogenic singalosomes [52], (d) expression of Epstein Barr virus (EBV) latent membrane protein 2A (LMP2A), and high levels of activated Ras protein $[53,54]$, (e) expression of the $\mathrm{K} 1$ protein of Kaposi's sarcoma-associated herpesvirus [55], (f) overexpression of the phosphodiesterase PDE4B gene and protein [56, 57], (g) overexpression of the T-cell leukemia/lymphoma 1 (TCL1) oncoprotein [58], (h) point mutations or amplification of the PI3K catalytic subunit alpha (PIK3CA) gene [29], and (i) genetic or epigenetic downregulation of phosphatase and tensin homolog (PTEN) suppressor gene $[34,35,59,60]$. As for the latter, a very recent study in animal models, showed that PTEN cooperates with another negative modulator of PI3K-mediated signaling, the Src homology 2 domaincontaining inositol phosphatase (SHIP), in order to suppress lymphoma pathogenesis [61].

Molecular alterations that activate the PI3K/Akt pathway could explain in part the upregulation of mTORC1 signaling in B-cell lymphomas (Figure 1(a)). The Raf/MEK/ERK pathway is another candidate inducer of mTORC1 activity in HLs and NHLs (Figure 1(b)). The fact that, on one hand, this pathway is another major upstream effector of mTORC1 and, on the other hand, it is activated in a subset of B-cell lymphomas justifies this hypothesis [2426, 31, 38, 39, 42, 45] (Table 1). Indeed, there is evidence that upregulated Raf/MEK/ERK pathway may contribute to elevated mTORC1 signaling in the setting of follicular lymphoma (FL) and HL [25, 40, 42]. Apart from Erk, p38 is another mitogen-activated protein (MAP) kinase which was recently suggested to induce mTORC1 activity [13] and that may also become dysregulated in lymphomas [25, 62-64] (Figure 1(c)). Moreover, there is evidence for a role of the activated TK Syk in the upregulation of mTORC1 activity in FL, diffuse large B-cell lymphoma (DLBCL), mantle cell lymphoma (MCL), and Burkitt lymphoma (BL) cells. Notably, Syk-in-duced mTORC1 activation in FL cells appears not to be PI3K/Akt dependent [40]. Furthermore, Syk gene amplification and elevated protein expression was found in Jeko-1 MCL cell line and a few MCL tissue samples. These alterations could potentially be related to the activation of Syk protein and mTORC1 [65]. In addition, phospholipase D (PLD) seems to mediate mTORC1 stimulation in two FL cell lines, while its possible implication 
TABLE 1: Evidence of aberrant activation of mTORC1, PI3K/Akt, and Raf/MEK/ERK pathways in B-cell lymphomas.

\begin{tabular}{|c|c|c|c|c|}
\hline Lymphoma Type & mTORC1 activation & PI3K/Akt activation & MEK/ERK dysregulation & Ref/s \\
\hline \multirow{4}{*}{$\begin{array}{l}\text { Hodgkin Lymphoma } \\
\text { (HL) }\end{array}$} & Cell lines, tissue samples & Cell lines, tissue samples & & {$[22]$} \\
\hline & Tissue samples & & & {$[23,24]$} \\
\hline & Tissue samples & Tissue samples & Tissue samples & {$[25]$} \\
\hline & & & Cell lines, tissue samples & {$[26]$} \\
\hline \multirow{5}{*}{$\begin{array}{l}\text { Mantle Cell Lymphoma } \\
\text { (MCL) }\end{array}$} & Cell lines, tissue samples & Cell lines, tissue samples & & {$[27,28]$} \\
\hline & Cell lines & Cell lines, tissue samples & & {$[28]$} \\
\hline & & Cell lines, tissue samples & & [29] \\
\hline & Tissue samples & & & {$[30]$} \\
\hline & $\begin{array}{l}\text { Cell lines, Lymphoma } \\
\text { cells from a MCL patient }\end{array}$ & $\begin{array}{l}\text { Cell lines, Lymphoma cells } \\
\text { from a MCL patient }\end{array}$ & $\begin{array}{l}\text { Cell lines, Lymphoma cells } \\
\text { from a MCL patient }\end{array}$ & {$[31]$} \\
\hline \multirow{5}{*}{$\begin{array}{l}\text { Diffuse Large B-Cell } \\
\text { Lymphoma (DLBCL) }\end{array}$} & Tissue samples & Tissue samples & & {$[32]$} \\
\hline & Cell lines, tissue samples & Cell lines & & {$[33]$} \\
\hline & & Tissue samples & & {$[34,35]$} \\
\hline & & Cell lines, tissue samples & & {$[36,37]$} \\
\hline & & Cell lines & Cell lines & {$[38,39]$} \\
\hline \multirow{5}{*}{$\begin{array}{l}\text { Follicular Lymphoma } \\
\text { (FL) }\end{array}$} & Cell lines, tissue samples & & & {$[40]$} \\
\hline & Cell lines & & Cell lines & {$[41]$} \\
\hline & Cell lines & Cell lines & & {$[42]$} \\
\hline & & Cell lines & & {$[43,44]$} \\
\hline & & Cell lines & Cell lines & {$[45]$} \\
\hline \multirow{2}{*}{ Burkitt Lymphoma } & Cell lines & & & {$[24]$} \\
\hline & & Cell lines & Cell lines & {$[32,46]$} \\
\hline \multirow{2}{*}{$\begin{array}{l}\text { Primary Effusion } \\
\text { Lymphoma (PEL) }\end{array}$} & $\begin{array}{l}\text { Cell lines, animal model } \\
\text { (mice) }\end{array}$ & $\begin{array}{l}\text { Cell lines, animal model } \\
\text { (mice) }\end{array}$ & & {$[47,48]$} \\
\hline & Cell lines & & Cell lines & {$[24]$} \\
\hline
\end{tabular}

in mTORC1 activation in other lymphomas deserves further investigation [40] (Figure 1(d)). There are also data suggesting the contribution of serine/threonine kinase 11 (LKB1), a tumor suppressor kinase which negatively regulates mTORC1 activity, in lymphoma pathogenesis in animal models. However, whether LKB1 participates in human lymphoid malignancy induction remains uncertain at present [66] (Figure 1(e)). On the other hand, in a study in B-cell lymphoma cell lines mTORC1 upregulation was shown to be dependent on nutrients but not on other known upstream effectors [46]. As regards more proximal effectors of mTORC1, elevated levels of Rheb mRNA were found in some aggressive NHLs through an unknown mechanism and in individual cases of high increase were related to mTORC1 activation [67]. Finally, amplification of the RPS6KB1 gene, which encodes for p70S6/p85S6 protein, has been described in one third of a series of DLBCLs with unknown functional significance in mTORC1 signaling [33].

\section{4. mTOR Inhibitors}

4.1. Rapamycin and Rapalogs. The prototype of classical mTOR inhibitors is sirolimus [14]. The mechanism of action of sirolimus is rather complicated since it may inhibit mTO$\mathrm{RC} 1$ or both the two mTOR complexes and either increase or in reduce Akt phosphorylation. These pharmaceutical effects are dependent on dose concentration, time after administration, and cell type [68-70]. Treatment with sirolimus may also activate ERK. Furthermore, sirolimus differentially affects the major substrates of mTORC1, S6K1 and 4E-BP1. It seems to downregulate $\mathrm{S} 6 \mathrm{~K} 1$, in most cell types, while in contrast inhibition of 4E-BP1 does not last long after treatment and is also cell specific. Consequently, a recovery in cap-dependent translation may be induced [17]. In malignant B-cells, sirolimus may cause cell cycle arrest, reduce proliferation, and inhibit growth in culture or delay tumor progression in animal models $[47,49,70-72]$. In addition, it may act similarly to amino acid deficiency as a positive modulator of genes which regulate nutrient catabolism and energy production and as a negative modulator of genes involved in the anabolic procedures of proteins, lipids, and nucleotides [73]. Moreover, it may potentiate the in vitro cytotoxicity of the chemotherapeutic agent doxorubicin, and the histone deacetylase inhibitor LBH $[22,70]$. Of interest, sirolimus exhibits immunosuppressant properties and has been widely administered in patients with organ transplantation [3]. In addition, it may induce autophagy, both when given as monotherapy or in combination to radiation or dexamethasone [74-76].

Second generation rapamycin derivatives (rapalogs) with more favorable pharmacokinetic properties than the parent 


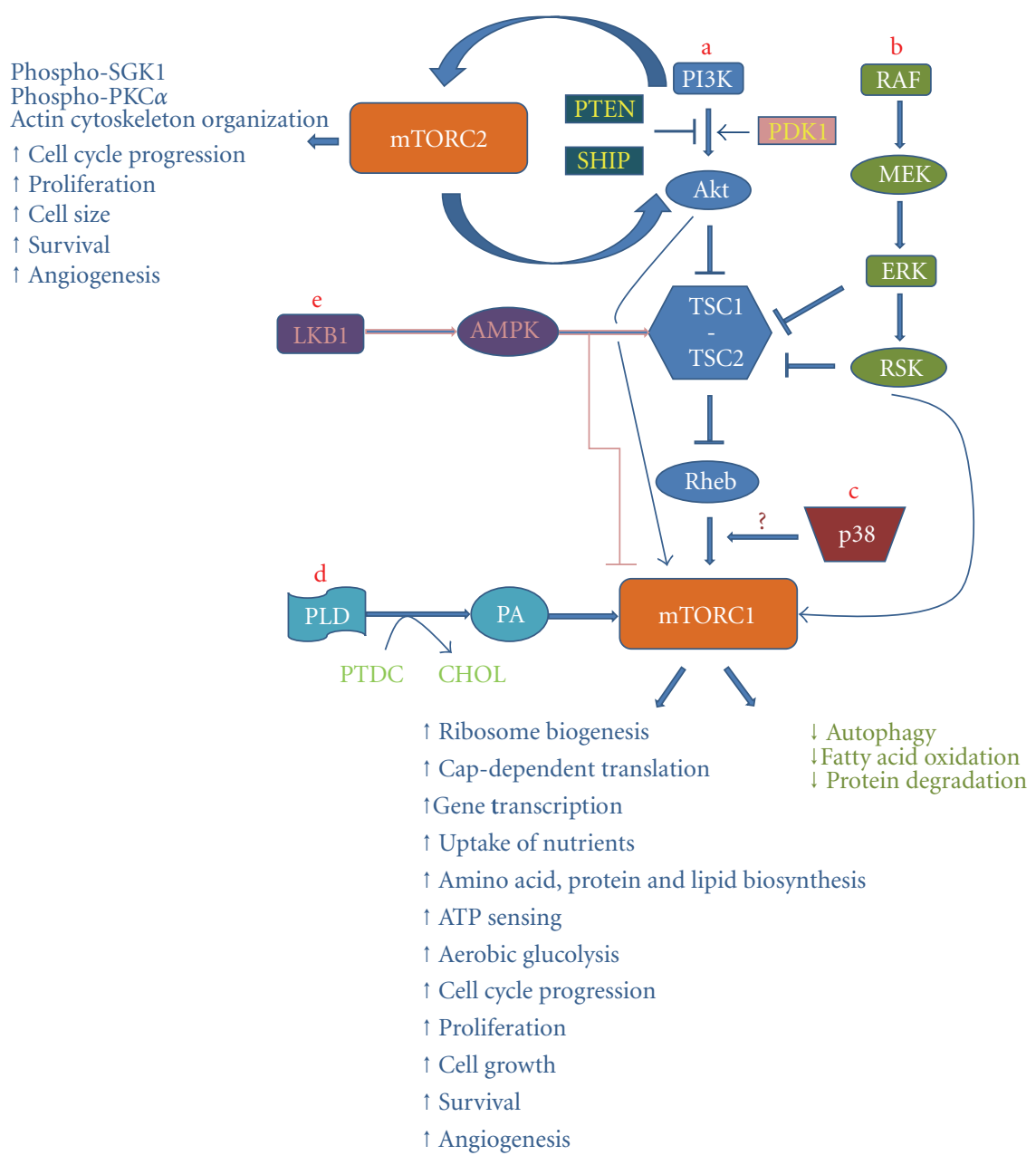

FIGURE 1: Molecular signaling cascades which normally control mTORC1 activity and may become dysregulated in B-cell lymphomas leading to aberrant mTORC1 signaling activation. The figure also demonstrates the functions of mTORC1 and mTORC2. (a) PI3K/Akt pathway: upon activation PI3K most possibly induces mTORC2 complex stimulation and also promotes the translocation of Akt and PDK1 to the cell membrane, where Akt becomes activated by PDK1 and mTORC2. Then, Akt activates mTORC1 by way of two mechanisms: (1) indirectly through downregulation of the inhibitory effect of the TSC1-TSC2 complex on Rheb protein and (2) directly through phosphorylation of PRAS40 (proline-rich Akt substrate of 40 kilodaltons), which is a component of the mTORC1 complex. The tumor suppressor phosphatases PTEN and SHIP oppose PI3K-mediated Akt activation. (b) RAF/MEK/ERK pathway: once activated this pathway triggers mTORC1 activity indirectly through inactivation of the TSC1-TSC2 complex by ERK and RSK (ribosomal S6 kinase, $90 \mathrm{kDa}$ ). The RAF/MEK/ERK pathway also directly activates mTORC1 through excitatory phosphorylation of raptor, a component of the mTORC1 complex, by RSK. (c) p38 is suggested to induce mTORC1 activity by acting downstream of or in parallel to Rheb. (d) PLD/phosphatidic acid (PA) pathway: upon activation PLD hydrolyzes phosphatidylcholine (PTDC) to generate choline (CHOL) and PA. Subsequently, PA activates mTORC1 by an unknown mechanism. (e) LKB1/AMP-dependent protein kinase (AMPK) pathway: the tumor suppressor kinase LKB1 activates AMPdependent protein kinase (AMPK). AMPK, in turn, inhibits mTORC1 through activation of the TSC1-TSC2 complex and direct inhibitory phosphorylation of raptor.

molecule, facilitating their clinical use, have been developed [77]. Currently, three of these chemical agents are available for clinical trials: temsirolimus (CCI-779, Torisel, Wyeth Pharmaceuticals), everolimus (RAD001, Affinitor, Novartis Pharmaceuticals), and ridaforolimus (AP23573, ARIAD Pharmaceuticals, formerly deforolimus) [78]. Similarly to rapamycin, rapalogs inhibit mTORC1, may downregulate mTORC2, and exert either excitatory or inhibitory effects on Akt protein, both in vitro and in vivo. Moreover, these effects depend on tumor-specific characteristics, dose, and schedule of treatment $[70,79,80]$. In B-cell lymphomas rapalogs exhibit antiproliferative, cytostatic, and antiangiogenic properties and may also trigger autophagy. In contrast, they appear to have minimal or no effect on survival of malignant cells $[70,81,82]$. Despite many theoretical gaps concerning rapalogs' mechanism of action, clinical trials with these agents show promising results in lymphoid neoplasms, apparently at the appropriate molecular background.

The pharmacokinetic and pharmacodynamic profiles of rapalogs differ. Temsirolimus is available in oral and 
TABLE 2: Ongoing clinical trials with rapalogs in patients with NHL.

\begin{tabular}{lccl}
\hline Phase & Locations & Clinical trial gov. number & Additional information \\
\hline I/II & USA & NCT01076543 & Lenalidomide and Temsirolimus in patients with relapsed or refractory HL or NHL \\
\hline I/II & USA & NCT00787969 & Rituximab, Cladribe, and Temsirolimus in patients with newly diagnosed MCL \\
\hline I/II & GERMANY & NCT01078142 & Temsirolimus, Bendamustine, and Rituximab for relapsed FL or MCL (BERT) \\
\hline I/II & USA & NCT00474929 & Everolimus and sorafenib for relapsed or refractory NHL, HL, or MM \\
\hline I & Cleveland OH & NCT00671112 & Everolimus plus bortezomibe for relapsed/refractory MCL and other NHL \\
\hline I/II & USA & NCT00967044 & $\begin{array}{l}\text { Panobinostat (LBH589) plus Everolimus (RAD001) in patients with relapsed and } \\
\text { refractory Lymphoma }\end{array}$ \\
\hline I/II & USA & NCT 101075321 & $\begin{array}{l}\text { Everolimus and Lenalidomide in treating patients with relapsed or refractory NHL } \\
\text { or HL }\end{array}$ \\
\hline I/II & USA & NCT00918333 & Panobinostat and Everolimus in treating patients with recurrent MM, NHL, or HL \\
\hline II & USA & NCT00869999 & Everolimus plus Rituximab for relapsed/refractory DLBCL \\
\hline I/II & USA & NCT00704054 & Deferolimus for relapsed/refractory NHL/HL \\
\hline
\end{tabular}

intravenous formulations. Upon administration, it is rapidly converted to rapamycin, its primary active metabolite [83]. Phase I dose-finding studies for temsirolimus aimed to establish a maximum-tolerated dose through dose escalation, by testing either a schedule of a daily administration of $0.75 \mathrm{mg} / \mathrm{m}^{2}$ IV every other week with a $20 \%$ dose escalation or a weekly schedule of doses ranging from $7.5 \mathrm{mg}-$ $220 \mathrm{mg} / \mathrm{m}^{2} \mathrm{IV}$ [83, 84]. Maximum tolerated dose was not established but the maximum acceptable dose was $19 \mathrm{mg} / \mathrm{m}^{2} /$ day due to grade 3 stomatitis. Although temsirolimus was found to be well tolerated, the most common toxicities included neutropenia, thrombocytopenia, asthenia, diarrhea, and stomatitis. The severity of its adverse effects was dose related. Because drug activity ceased to increase after several dose levels, phase I studies supported the use of a flat dose for temsirolimus and the suggested dose for phase II studies was 25,75 , or $250 \mathrm{mg}$ weekly.

Everolimus is orally available and typically administrated on a daily schedule. It has been also been tested on a weekly basis, mostly in combination regimens. Phase I studies showed that the efficacy of the drug was dose dependent and that mTOR inhibition was more profound with daily dosing. In addition, everolimus was found to have acceptable tolerability at the highest doses studied. The suggested dose for phase II studies was $10 \mathrm{mg}$ daily or $50-70 \mathrm{mg}$ weekly $[85,86]$.

Ridaforolimus, unlike temsirolimus, is not a prodrug [87], and it is given typically intravenously, although oral administration is currently under clinical testing [88]. Phase I studies tested a daily regimen of $3-28 \mathrm{mg}$ and found that mTOR inhibition increased in a less than proportional manner. Maximum tolerated dose was $18.75 \mathrm{mg}$ daily due to grade 3 mouth sores and a dose of $12 \mathrm{mg}$ IV daily was proposed as suitable for phase II studies [87].

At present, numerous clinical trials are under way in order to evaluate the above drugs as single agents or in combination in aggressive and/or refractory lymphomas (Table 2) (http://www.cancer.gov/search/ResultsClinicalTrials).

\section{Clinical Trials with Rapalogs in Lymphomas}

5.1. Mantle Cell Lymphoma. Mantle Cell Lymphoma (MCL) is an aggressive type of mature B-cell lymphoid neoplasm with a relative frequency of $7 \%$ among NHLs. The genetic hallmark of MCL is the translocation $\mathrm{t}(11 ; 14)$ (q13; $\mathrm{q} 32$ ), which results in overexpression of cyclin D1 [89]. It is characterized by an aggressive clinical course and poor prognosis with median survival of 3 to 5 years [90]. Although front treatment induces a high rate of complete remission (CR), relapse is common. Therefore, new therapies are needed [91]. Aberrant activation of mTORC1 as well as PI3K/Akt signaling is frequent in the MCL $[27,28,30,49]$.

Additionally, in preclinical MCL models both temsirolimus and everolimus showed anti-proliferative effects, especially in combination with other therapeutic agents, such as vorinostat, doxorubicin, and vortezomib [81, 82, 92, 93].

Among rapalogs, temsirolimus has been thoroughly studied in clinical trials in MCL. In two phase II studies and in one large randomized phase III study performed by North Central Cancer Treatment Group (NCCTG), temsirolimus was found to display significant antitumor activity and clinical benefit as a single therapeutic agent in relapsed or refractory MCL. The first of phase II studies conducted by Witzig et al., assessed the efficacy of a $250 \mathrm{mg} /$ week IV course of temsirolimus monotherapy in 35 patients with relapsed or refractory MCL that had received previous treatment. The overall response rate (ORR) was $38 \%$, with one complete remission (CR) and one partial remission (PR) [94]. In the second phase II study, Ansell et al. administered a 10-fold lower dose of temsirolimus ( $25 \mathrm{mg}$ weekly IV) in 29 patients with relapsed or refractory MCL and achieved a similar ORR (41\%) with one CR and ten PRs. However, the lower dose was associated with lower rates of toxicity (50\% versus $71 \%$ grade 3 and $4 \%$ versus $11 \%$ grade 4 ) [95]. In both studies, thrombocytopenia was the most common adverse effect and the most frequent cause of dose reduction. In addition, both studies included adults (median age 70 years old) that had 
failed previous therapies with rituximab (monoclonal antiCD20 antibody), cyclophosphamide, or doxorubicin [94, 95].

Based on these results, a randomized, large phase III study was conducted to evaluate the effect of temsirolimus in comparison to investigator's choice therapy in 162 patients with relapsed/refractory MCL, previously treated with rituximab, alkylating agents, and anthracycline. The patients were randomized to receive treatment with temsirolimus applied in one of two therapeutic schemes $(175 \mathrm{mg} /$ week for three weeks followed by either $25 \mathrm{mg}$ or $75 \mathrm{mg}$ weekly IV) or treatment with a single agent of the investigator's choice from approved protocols. It was shown that ORR was significantly higher in patients who received the $75 \mathrm{mg}$ dose of temsirolimus compared to treatment with the investigator's choice agent (22\% versus $2 \%, P=.0019)$. Median progression free survival (PFS) was also longer (4.8 months versus 1.9 months). Regarding patients who received $25 \mathrm{mg}$ temsirolimus, ORR was 6\% and PFS 3.4 months. Similar to the previous trials, hematological toxicity was the most frequent adverse effect. This study demonstrated that administration of 175/75 mg temsirolimus improved ORR and PFS significantly and showed a trend toward longer overall survival (OS) [96]. The results of this trial led to the European approval of temsirolimus as single agent therapy for the treatment of relapsed/refractory MCL [97].

More recently, Ansell et al. reported the results of the first phase II study that examined the efficacy of temsirolimus in combination with rituximab in patients with relapsed or refractory MCL [98]. In this study 69 patients were treated with temsirolimus $(25 \mathrm{mg} /$ week $)$ and rituximab $\left(375 \mathrm{mg} / \mathrm{m}^{2}\right.$ per week) for 4 weeks during the first cycle followed by a single dose of rituximab every other 28-day cycle for a total of 12 cycles. The ORR was 59\% consisting of 19\% CRs and $41 \%$ PRs. The ORR was $63 \%$ for rituximab-sensitive patients and $52 \%$ for rituximab-refractory patients. The median time to progression (TTP) for all patients was 9.7 months (10.9 months in the rituximab-sensitive patients and 5.4 months in the rituximab-refractory patients). The most common side-effect was hematological toxicity which did not differ from that in the previous studies of temsirolimus alone. Additionally, the other more frequent grades 3 and 4 toxicities included increased serum concentrations of cholesterol and triglycerides, hyperglycaemia, fatigue, and dyspnoea. The frequencies of these toxicities were also similar to that of temsirolimus as monotherapy suggesting that rituximab can be safely combined with temsirolimus without much increase in toxicity. The above results are promising with much higher ORR and CR rate than in the phase III study of temsirolimus alone without increasing toxicity [96]. However, more randomized trials are needed in order to establish the effectiveness of the combination of temsirolimus plus rituximab in the treatment of relapsed or refractory MCL patients.

The efficacy of everolimus in MCL was investigated in phase II clinical trials. Witzig et al. demonstrated the antitumor activity of the drug when applied as monotherapy in relapsed/refractory NHLs. In this trial, 19 patients with MCL, 47 patients with DLBCL and 3 patients with FL were included. Daily dose was $10 \mathrm{mg}$ PO. All patients had been heavily pretreated with a median of three previous therapies and $32 \%$ of them had undergone autologous stemcell transplantation. In this study, ORR in patients with MCL was $32 \%$, lying in the middle of the $40 \%$ and $22 \%$ that were found in the two phase II and the one phase III trials of temsirolimus, respectively. In addition, ORR in DLBCL patients was $30 \%$ and in FL patients $38 \%$. Hematological toxicity, mainly thrombocytopenia $(38 \%)$, was again the most frequent adverse effect. Grade 3 or 4 toxicity was observed in $68 \%$ of the patients, which was managed easily with dose interruption or reduction [99]. On the other hand, in another phase I/II study designed to evaluate everolimus effect in 26 patients with hematological malignancies including MCL, none of the 4 patients with MCL responded to everolimus [93].

Furthermore, in the setting of MCL the activity of ridaforolimus has been evaluated as well. In a phase II study, 55 heavily pretreated patients with various hematological malignancies, including 9 patients with MCL, received ridaforolimus as single agent ( $12.5 \mathrm{mg}$ IV once a week every 2 weeks). The most favorable response was observed in MCL patients, with 33\% ORR and three PRs. Although the number of MCL patients involved in this study was small, it cannot be ignored that ORR achieved with ridaforolimus is similar to that demonstrated in the two phase II studies of single agent temsirolimus in MCL. Additionally, the fact that $44 \%$ of MCL patients had stable disease and only two experienced progressive disease probably reflects a promising antitumor activity of ridaforolimus that has to be further investigated. It is also noteworthy that ridaforolimus was well tolerated. Mouth sores was the most frequent adverse effect, while thrombocytopenia was less commonly encountered than with other rapamycin derivatives [100].

In summary, temsirolimus is the most extensively studied mTOR inhibitor in the setting of MCL, which has been shown to significantly improve objective response and progression-free survival compared to investigator's choice therapy in patients with relapsed/refractory MCL in a phase III clinical trial. The effectiveness of temsirolimus in combination to immunotherapy or chemotherapy has already been under investigation. Everolimus and ridaforolimus have demonstrated promising antitumor activity against MCL but further investigation is needed in order to evaluate their potential efficacy.

5.2. Diffuse Large B-Cell Lymphoma (DLBCL). Diffuse large B-cell lymphoma (DLBCL) represents almost one third of all NHL subtypes [90]. Although standard chemotherapy regimens (R-CHOP, rituximab-cyclophospamide, doxorubicin, vincristine, and prednisone) have shown effectiveness in the treatment of DLBCL, there is still a group of patients that die from the disease [101].

In preclinical studies, rapamycin analogue everolimus has been found to induce G1 cell-cycle arrest but not apoptosis in DLBCL cell lines of the germinal centre (GC) type and to increase the cytotoxicity of rituximab $[71,102]$. 
Temsirolimus has shown promising results as a single agent in DLBCL in a phase II study performed by University of Chicago. The study included 89 pretreated patients with either DLBCL, follicular lymphoma (FL), chronic lymphocytic leukemia (CLL), or other indolent lymphomas that were stratified in three groups. Patients received a weekly course of temsirolimus of $25 \mathrm{mg}$. It was found that DLBCL patients had an ORR of $28.1 \%$ with four CRs and 5 PRs (9 patients out of 32). This result is promising, taking into account that all patients were heavily pretreated; however, the durability of response was short (2.4 months). Based on the fact that nearly half of DLBCL responders had transformed from a prior FL, authors suggest that temsirolimus might be more active in follicle center derived lymphomas. The most common adverse effect of temsirolimus was myelosuppression, which was reversible, while other toxicities included stomatitis and metabolic dysregulation mainly grade one or two [103].

Everolimus has also been tested in clinical trials in DLBCL, demonstrating response rates similar to temsirolimus. In a phase II study by Witzig et al. that included 77 patients with DLBCL, FL, or MCL, the ORR in DLBCL patients was 30\% (14 out of 47) [99]. However, the duration of response was longer than with temsirolimus (5.7 months). On the other hand, compared to the previous study with temsirolimus where 4 CRs were observed, no patient among DLBCL group who were treated with everolimus achieved a CR. The most important adverse effect in this study was grade 3 or 4 hematologic toxicity, which appeared in $68 \%$ of patients [103].

Deferolimus has not been investigated yet as a single agent in the treatment of DLBCL or other NHL subtypes. However, preliminary results show antitumor activity in many tumor types and numerous ongoing clinical trials are under way (Table 2) [87].

5.3. Follicular Lymphoma (FL). Follicular lymphoma (FL) is the second most common type of B-NHL in the West, accounting for $25-35 \%$ of all NHLs [90]. Patients with FL usually have an indolent clinical course, but they might eventually evolve to a refractory phase that can lead to death. Activation of mTOR pathway has been demonstrated in FL cell lines and tissue samples [40-42]. It has also been shown that mTOR activation in FL cell lines is enhanced by Syk independently of Akt and also by PLD [40]. However, mTOR inhibitors have not been tested in FL cell lines or animal models.

Both temsirolimus and everolimus have shown effectiveness in relapsed FL in phase II studies. In the above mentioned study from University of Chicago, patients with FL demonstrated an ORR of $53.8 \%$ with CR rates reaching $25.6 \%$. Furthermore, median duration of response was 13 months, much longer than in DLBCL [103]. Similarly to temsirolimus, everolimus has shown antitumor activity in FL. In the previously mentioned phase II study by Witzig et al. the reported ORR in FL was 38\%, with a median duration of response of 5.7 months. Of note, this study included only patients with FL grade 3 [99]. These results are very promising, but they need to be validated in further studies that will include larger groups of patients.

5.4. Hodgkin's Lymphoma (HL). Hodgkin's Lymphoma (HL) represents $30 \%$ of all lymphoma cases. It is characterized by the presence of neoplastic Hodgkin and Reed-Steinberg cells (HRS) in a background of inflammatory and accessory cells [90]. Although it has proven a highly curable disease, there is a subset of patients that either relapse after salvage chemotherapy or do not respond due to old age. Consequently, there is still need for new therapeutic approaches.

Various studies have demonstrated activation of the mTOR pathway in HL cell lines and primary tumors [104107]. The mechanism of mTOR activation in HL has not been clarified yet, but Akt is considered to play a role since phosporylated Akt has been reported to be activated in HL tumors [22, 108]. In HRS cells, rapamycin induces G1-S cell cycle arrest but not apoptosis and enhances the cytotoxic activity of doxorubicin [109]. Among rapamycin analogues, temsirolimus has been reported to induce cell cycle arrest followed by autophagy in HL cell lines [110]. In addition, everolimus has been demonstrated to have antiproliferative results in HRS cells. Furthermore, it has been shown to be effective in HL murine xenograft models [109].

Based on preclinical studies, a phase II study assessed the effectiveness of everolimus in patients with refractory/ relapsed HL. This study evaluated a total of 19 patients with relapsed/refractory HL as part of a larger study evaluating everolimus in more rare forms of lymphoma. Patients had a median age of 37 years and had received a median of six prior therapies. They were treated with a daily oral dose of $10 \mathrm{mg}$ and response was evaluated after two and six cycles of therapy. The ORR was 47\%, with 8 PRs and one CR. Among those patients, 4 remained progression free at 12 years and 1 remains on therapy for more than 3 years. Of note, $74 \%$ patients experienced grade 3 or 4 toxicity. Although hematological toxicity was the most common adverse effect, a subset of patients (11\%) developed pulmonary symptoms, such as dyspnea and cough that required dose reductions. This high rate of toxicity should be a matter of concern in older patients. Overall, the results of this study are encouraging, if we take into account that responders had stable disease on everolimus for a long period. The authors suggest that combination of everolimus with other agents might be even more effective [110].

\section{Specific and NonSpecific ATP-Competitive mTOR Inhibitors}

Recently a new category of mTOR inhibitors has come to prominence due to their ability to show a more profound impact on PI3K/Akt/mTOR pathway in relation to rapamycin and rapalogs. These drugs are small molecules that bind to the ATP-binding site of mTOR kinase and inhibit the catalytic activity of both mTOR complexes $[2,111-$ 122]. Two subclasses of agents are included here. The first subclass comprises of nonspecific ATP-competitive mTOR inhibitors, which apart from mTORC1 and mTORC2 also 
inhibit PI3Ks (Dual PI3K/mTOR inhibitors) [112-116]. The second subclass consists of drugs which selectively inhibit mTORC1 and mTORC2 without affecting other kinases [111, 117-122]. These molecules are known with different names such as specific active-site TOR inhibitors (asTORi) and TOR kinase domain inhibitors (TORKinibs) [2, 115, 123].

\section{Dual PI3K/mTOR Inhibitors}

This subclass of ATP-competitive mTOR inhibitors includes several molecules which have been applied in preclinical models in hematologic malignancies $[2,27,28,49,102,116$, 124, 125]. Two of these agents, LY294002 and wortmannin, were initially described as PI3K inhibitors and later found to target mTOR as well [124]. With regard to B-cell lymphomas, both of them have been tried in MCL and FL cell lines and were shown to downregulate Akt and/or mTOR activity [27, 28, 40, 49]. In addition, LY294002 was shown to decrease cyclin D1 protein levels in MCL cells, suggesting induction of cell cycle arrest [27]. LY294002 was also applied on DLBCL cell lines and found to trigger apoptosis in 3 out of 5 cell lines in one study. In the same study two DLBCL cell lines excibited dephosphorylation of Akt upon LY294002 treatment [102]. Similar were the results regarding LY294002 effect on Akt inactivation in another study from China which also included DLBCL cell lines. Moreover, in this study, LY294002 decreased the ratio of $S$ phase and of interest exhibited synergistic effect with doxorubicin on triggering apoptosis [126]. Another dual PI3K/mTOR inhibitor, NVP-BEZ235 was recently tried in FL cell lines and was found to inhibit cell growth and proliferation due to increased apoptosis. Furthermore, it showed a synergistic activity with bortezomib against FL cell proliferation [116]. Furthermore, Bhatt et al. reported that NVP-BEZ235 suppressed proliferation in primary effusion lymphoma (PEL) cell lines and xenograft models, more efficiently than selective inhibitors of PI3K/Akt mTOR pathway [48]. Although results from preclinical trials with dual $\mathrm{PI} 3 \mathrm{~K} / \mathrm{mTOR}$ inhibitors are preliminary and further clinical trials are needed to confirm them, these agents seem that may be potentially effective in NHL treatment. Dual PI3K/mTOR inhibitors are currently being tested in phase I trials [112].

\section{Active-Site TOR Inhibitors (asTORi)}

All preclinical compounds in this category have been reported to have similar molecular behaviour, as they have been shown to reduce phosphorylation of both endogenous S6 kinase and Akt $[115,117-119,122]$. Interestingly, they are more effective mTORC1 inhibitors than rapamycin and rapalogs, since they completely inhibit S6 kinase and 4EBP1. Also, they trigger a more intense suppression on capdependent translation, protein synthesis, cell growth and proliferation $[2,115,117-119,122]$. In addition, asTORi may induce apoptosis and autophagy and in relation to rapalogs cause a more profound decrease of lactate as well as the angiogenic hypoxia inducible factors (HIFs) and vascular endothelial growth factor (VEGF) [121, 122]. Among asTORi agents used in clinical models, AZD8055 shows similar in vitro effects with PP42, Torin-1, and Ku-0063794. However, in contrast to these inhibitors AZD8055 has also been found to inhibit tumor cell proliferation in vivo [121]. More specifically, it induces a dose-dependent inhibition and/or regression in human tumor xenograft models which is associated with a dose-dependent pharmacodynamic effect on both phosphorylated S6 and phosphorylated Akt. AZD8055 is currently being evaluated in phase I studies [122]. PP42 and $\mathrm{Ku}-0063794$ are two other asTORi drugs which have shown important preclinical activity against hematological malignancies [2]. PP42 has been found to cause death to mouse and human $\mathrm{Ph}+\mathrm{B}-\mathrm{ALL}$ cells, with great selectivity to leukemia cells compared to normal bone marrow and peripheral blood lymphocytes [120]. Moreover, PP42 has shown marked therapeutic response in transgenic mice that develop thymic lymphomas [127]. Regarding another asTORi, OSI-027, it has been reported to generate antileukemic effects in BCR/ABL transformed cells. Based on this finding, it is currently being evaluated in phase I studies in solid as well as lymphoid neoplasms. Finally, INK128 has demonstrated broad preclinical antitumor activity against a range of solid tumor types and multiple myeloma [2]. Currently, it is also being evaluated in phase I studies. None of these inhibitors have been tested in clinical trials in lymphomas yet. Further studies are currently conducted aiming to elucidate the potential therapeutic effect of asTORi-s in neoplasms, including lymphomas.

\section{Conclusions}

Through the last years it has become clear that mTOR pathway contributes to the pathogenesis of hematological malignancies by playing a key role in the regulation of many cell functions, such as cell proliferation, cell growth, and angiogenesis. The development of mTOR inhibitors has opened a new field in the clinical arena of lymphomas. Temsirolimus has been recently approved for the treatment of relapsed/refractory mantle cell lymphoma. In addition, everolimus and deferolimus have been evaluated in phase II clinical trials that reveal their potential for the treatment of aggressive lymphomas, justifying further evaluation with randomized phase III trials. In addition to rapalogs, other types of mTOR inhibitors have been currently developed, with promising results in preclinical studies. In our opinion, future research on the use of mTOR inhibitors in lymphoid malignancies should aim in three basic fields: (a) identification of the whole spectrum of molecular alterations that are related to mTOR signaling dysregulation in each lymphoma subtype, (b) definition of the subset of patients who are likely to respond best to anti-mTOR treatment, and (c) design of new clinical trials aiming to determine the effectiveness of mTOR-inhibitors in the context of established or other; targeted or nontargeted; treatment. Undoubtedly, there is evidence-based hope that lymphoma treatment will be substantially improved in the next decade. 


\section{Acknowledgments}

P. Argyriou and P. Economopoulou contributed equally to this paper.

\section{References}

[1] P. B. Johnston, R. Yuan, F. Cavalli, and T. E. Witzig, "Targeted therapy in lymphoma," Journal of Hematology \& Oncology, vol. 3, p. 45, 2010.

[2] C. Vu and D. A. Fruman, "Target of rapamycin signaling in leukemia and lymphoma," Clinical Cancer Research, vol. 16, pp. 5374-5380, 2010.

[3] W. W. Ma and A. A. Adjei, "Novel agents on the horizon for cancer therapy," CA: Cancer Journal for Clinicians, vol. 59, no. 2, pp. 111-137, 2009.

[4] S. Wullschleger, R. Loewith, and M. N. Hall, "TOR signaling in growth and metabolism," Cell, vol. 124, no. 3, pp. 471-484, 2006.

[5] G. A. Soliman, "The mammalian target of rapamycin signalling network and gene regulation," Current Opinion in Lipidology, vol. 16, no. 3, pp. 317-323, 2005.

[6] K. Inoki, H. Ouyang, Y. Li, and K. L. Guan, "Signaling by target of rapamycin proteins in cell growth control," Microbiology and Molecular Biology Reviews, vol. 69, no. 1, pp. 79-100, 2005.

[7] K. G. Foster and D. C. Fingar, "Mammalian target of rapamycin (mTOR): conducting the cellular signaling symphony," Journal of Biological Chemistry, vol. 285, no. 19, pp. 14071-14077, 2010.

[8] T. R. Peterson, M. Laplante, C. C. Thoreen et al., "DEPTOR is an mTOR inhibitor frequently overexpressed in multiple myeloma cells and required for their survival," Cell, vol. 137, no. 5, pp. 873-886, 2009.

[9] S. Menon and B. D. Manning, "Common corruption of the mTOR signaling network in human tumors," Oncogene, vol. 27, supplement 2, pp. S43-S51, 2008.

[10] J. Huang and B. D. Manning, "The TSC1-TSC2 complex: a molecular switchboard controlling cell growth," Biochemical Journal, vol. 412, no. 2, pp. 179-190, 2008.

[11] R. M. Memmott and P. A. Dennis, "Akt-dependent and -independent mechanisms of mTOR regulation in cancer," Cellular Signalling, vol. 21, no. 5, pp. 656-664, 2009.

[12] J. A. McCubrey, L. S. Steelman, W. H. Chappell et al., "Roles of the Raf/MEK/ERK pathway in cell growth, malignant transformation and drug resistance," Biochimica et Biophysica Acta, vol. 1773, no. 8, pp. 1263-1284, 2007.

[13] M. Cully, A. Genevet, P. Warne et al., "A role for p38 stressactivated protein kinase in regulation of cell growth via TORC1," Molecular and Cellular Biology, vol. 30, no. 2, pp. 481-495, 2010.

[14] L. M. Ballou and R. Z. Lin, "Rapamycin and mTOR kinase inhibitors," Journal of Chemical Biology, vol. 1, pp. 27-36, 2008.

[15] N. Cybulski and M. N. Hall, "TOR complex 2: a signaling pathway of its own," Trends in Biochemical Sciences, vol. 34, no. 12, pp. 620-627, 2009.

[16] I. Tato, R. Bartrons, F. Ventura, and J. L. Rosa, "Amino acids activate mTOR complex 2 via PI3K/Akt signalling," Journal of Biological Chemistry, vol. 286, no. 8, pp. 6128-6142, 2011.

[17] A. Y. Choo and J. Blenis, "Not all substrates are treated equally Implications for mTOR, rapamycin-resistance and cancer therapy," Cell Cycle, vol. 8, no. 4, pp. 567-572, 2009.

[18] Q. Sun, X. Chen, J. Ma et al., "Mammalian target of rapamycin up-regulation of pyruvate kinase isoenzyme type
M2 is critical for aerobic glycolysis and tumor growth," Proceedings of the National Academy of Sciences, vol. 108, pp. 4129-4134, 2011.

[19] D. R. Alessi, L. R. Pearce, and J. M. García-Martínez, "New insights into mTOR signaling: mTORC2 and beyond," Science Signaling, vol. 2, no. 67, p. pe27, 2009.

[20] W. Li, M. Petrimpol, K. D. Molle, M. N. Hall, E. J. Battegay, and R. Humar, "Hypoxia-induced endothelial proliferation requires both mTORC1 and mTORC2," Circulation Research, vol. 100, no. 1, pp. 79-87, 2007.

[21] F. Zhang, X. Zhang, M. Li et al., "mTOR complex component Rictor interacts with PKCzeta and regulates cancer cell metastasis," Cancer Research, vol. 70, pp. 9360-9370, 2010.

[22] A. Dutton, G. M. Reynolds, C. W. Dawson, L. S. Young, and P. G. Murray, "Constitutive activation of phosphatidylinositide 3 kinase contributes to the survival of Hodgkin's lymphoma cells through a mechanism involving Akt kinase and mTOR," Journal of Pathology, vol. 205, no. 4, pp. 498506, 2005.

[23] R. E. Brown and N. R. Kamal, "p-p70S6K (Thr 389) expression in nodular sclerosing Hodgkin's disease as evidence for receptor tyrosine kinase signaling," Annals of Clinical and Laboratory Science, vol. 35, no. 4, pp. 413-414, 2005.

[24] M. El-Salem, P. N. Raghunath, M. Marzec et al., "Activation of mTORC1 signaling pathway in AIDS-related lymphomas," American Journal of Pathology, vol. 175, no. 2, pp. 817-824, 2009.

[25] J. De and R. E. Brown, "Tissue-microarray based immunohistochemical analysis of survival pathways in nodular sclerosing classical Hodgkin lymphoma as compared with Non-Hodgkin's lymphoma," International Journal of Clinical and Experimental Medicine, vol. 3, no. 1, pp. 55-68, 2010.

[26] B. Zheng, P. Flumara, Y. V. Li et al., "MEK/ERK pathway is aberrantly active in Hodgkin disease: a signaling pathway shared by CD30, CD40, and RANK that regulates cell proliferation and survival," Blood, vol. 102, no. 3, pp. 10191027, 2003.

[27] E. Peponi, E. Drakos, G. Reyes, V. Leventaki, G. Z. Rassidakis, and L. J. Medeiros, "Activation of mammalian target of rapamycin signaling promotes cell cycle progression and protects cells from apoptosis in mantle cell lymphoma," American Journal of Pathology, vol. 169, no. 6, pp. 2171-2180, 2006.

[28] M. Rudelius, S. Pittaluga, S. Nishizuka et al., "Constitutive activation of Akt contributes to the pathogenesis and survival of mantle cell lymphoma," Blood, vol. 108, no. 5, pp. 16681676, 2006.

[29] A. Psyrri, S. Papageorgiou, E. Liakata et al., "Phosphatidylinositol $3^{\prime}$-kinase catalytic subunit $\alpha$ gene amplification contributes to the pathogenesis of mantle cell lymphoma," Clinical Cancer Research, vol. 15, no. 18, pp. 5724-5732, 2009.

[30] P. Argyriou, S. G. Papageorgiou, V. Panteleon et al., "Hypoxia-inducible factors in mantle cell lymphoma: implication for an activated mTORC1 $\rightarrow$ HIF- $1 \alpha$ pathway," Annals of Hematology, vol. 90, pp. 315-322, 2011.

[31] J. B. Dennison, M. Shanmugam, M. L. Ayres et al., "8Aminoadenosine inhibits Akt/mTOR and Erk signaling in mantle cell lymphoma," Blood, vol. 116, pp. 5622-5630, 2010.

[32] B. H. Yu, X. Y. Zhou, X. Y. Xiao, S. Y. Yan, T. Qin, and D. R. Shi, "Activation and clinicopathologic significance of AKT/mTOR signaling pathway in diffuse large B-cell lymphoma," Chinese Journal of Pathology, vol. 38, no. 1, pp. 35-41, 2009.

[33] M. Y. Zhao, A. Auerbach, A. M. D'Costa et al., "Phosphop70S6K/p85S6K and cdc2/cdk1 are novel targets for diffuse 
large B-cell lymphoma combination therapy," Clinical Cancer Research, vol. 15, no. 5, pp. 1708-1720, 2009.

[34] Y. Baohua, Z. Xiaoyan, Z. Tiecheng, Q. Tao, and S. Daren, "Mutations of the PIK3CA gene in diffuse large B cell lymphoma," Diagnostic Molecular Pathology, vol. 17, no. 3, pp. 159-165, 2008.

[35] J. Abubaker, P. P. Bavi, S. Al-Harbi et al., "PIK3CA mutations are mutually exclusive with PTEN loss in diffuse large B-cell lymphoma," Leukemia, vol. 21, no. 11, pp. 2368-2370, 2007.

[36] S. Uddin, R. Bu, M. Ahmed et al., "Leptin receptor expression and its association with PI3K/AKT signaling pathway in diffuse large B-cell lymphoma," Leukemia and Lymphoma, vol. 51, no. 7, pp. 1305-1314, 2010.

[37] S. H. Kuo, P. Y. Yeh, L. T. Chen et al., "Overexpression of B cell activating factor of TNF family (BAFF) is associated with Helicobacter pylori independent growth of gastric diffuse large B-cell lymphoma with histologic evidence of MALT lymphoma," Blood, vol. 112, no. 7, pp. 2927-2934, 2008.

[38] E. P. M. Tjin, R. W. J. Groen, I. Vogelzang et al., "Functional analysis of HGF/MET signaling and aberrant HGF-activator expression in diffuse large B-cell lymphoma," Blood, vol. 107, no. 2, pp. 760-768, 2006.

[39] R. E. Davis, V. N. Ngo, G. Lenz et al., "Chronic active B-cellreceptor signalling in diffuse large B-cell lymphoma," Nature, vol. 463 , no. 7277, pp. 88-92, 2010.

[40] L. Leseux, S. M. Hamdi, T. Al Saati et al., "Syk-dependent mTOR activation in follicular lymphoma cells," Blood, vol. 108, no. 13, pp. 4156-4162, 2006.

[41] M. Gupta, S. R. Dillon, S. C. Ziesmer et al., "A proliferationinducing ligand mediates follicular lymphoma B-cell proliferation and cyclin D1 expression through phosphatidylinositol 3-kinase-regulated mammalian target of rapamycin activation," Blood, vol. 113, no. 21, pp. 5206-5216, 2009.

[42] L. Leseux, G. Laurent, C. Laurent et al., "PKC $\zeta$-mTOR pathway: a new target for rituximab therapy in follicular lymphoma," Blood, vol. 111, no. 1, pp. 285-291, 2008.

[43] H. Zha, M. Raffeld, L. Charboneau et al., "Similarities of prosurvival signals in Bcl-2-positive and Bcl-2-negative follicular lymphomas identified by reverse phase protein microarray," Laboratory Investigation, vol. 84, no. 2, pp. 235$244,2004$.

[44] C. Gulmann, V. Espina, E. Petricoin III et al., "Proteomic analysis of apoptotic pathways reveals prognostic factors in follicular lymphoma," Clinical Cancer Research, vol. 11, no. 16, pp. 5847-5855, 2005.

[45] K. R. Calvo, B. Dabir, A. Kovach et al., "IL-4 protein expression and basal activation of Erk in vivo in follicular lymphoma," Blood, vol. 112, no. 9, pp. 3818-3826, 2008.

[46] P. Wlodarski, M. Kasprzycka, X. Liu et al., "Activation of mammalian target of rapamycin in transformed B lymphocytes is nutrient dependent but independent of Akt, mitogenactivated protein kinase/extracellular signal-regulated kinase kinase, insulin growth factor-1, and serum," Cancer Research, vol. 65, no. 17, pp. 7800-7808, 2005.

[47] S. H. Sin, D. Roy, L. Wang et al., "Rapamycin is efficacious against primary effusion lymphoma (PEL) cell lines in vivo by inhibiting autocrine signaling," Blood, vol. 109, no. 5, pp. 2165-2173, 2007.

[48] A. P. Bhatt, P. M. Bhende, S. H. Sin, D. Roy, D. P. Dittmer, and B. Damania, "Dual inhibition of PI3K and mTOR inhibits autocrine and paracrine proliferative loops in PI3K/Akt/mTOR-addicted lymphomas," Blood, vol. 115, no. 22, pp. 4455-4463, 2010.

[49] J. D. Col, P. Zancai, L. Terrin et al., "Distinct functional significance of Akt and mTOR constitutive activation in mantle cell lymphoma," Blood, vol. 111, no. 10, pp. 51425151, 2008.

[50] X. Lu, H. Nechushtan, F. Ding et al., "Distinct IL-4-induced gene expression, proliferation, and intracellular signaling in germinal center B-cell-like and activated B-cell-like diffuse large-cell lymphomas," Blood, vol. 105, no. 7, pp. 2924-2932, 2005.

[51] C. Renné, K. Willenbrock, J. I. Martin-Subero et al., "High expression of several tyrosine kinases and activation of the PI3K/AKT pathway in mediastinal large B cell lymphoma reveals further similarities to Hodgkin lymphoma," Leukemia, vol. 21, no. 4, pp. 780-787, 2007.

[52] S. Tauzin, H. Ding, D. Burdevet, B. Borisch, and D. C. Hoessli, "Membrane-associated signaling in human B-lymphoma lines," Experimental Cell Research, vol. 317, pp. 151$162,2011$.

[53] T. Portis and R. Longnecker, "Epstein-Barr virus (EBV) LMP2A mediates B-lymphocyte survival through constitutive activation of the Ras/PI3K/Akt pathway," Oncogene, vol. 23, no. 53, pp. 8619-8628, 2004.

[54] R. Swart, I. K. Ruf, J. Sample, and R. Longnecker, "Latent membrane protein 2A-mediated effects on the phosphatidylinositol 3-kinase/Akt pathway," Journal of Virology, vol. 74, no. 22, pp. 10838-10845, 2000.

[55] C. C. Tomlinson and B. Damania, "The K1 protein of Kaposi's sarcoma-associated herpesvirus activates the akt signaling pathway," Journal of Virology, vol. 78, no. 4, pp. 1918-1927, 2004.

[56] P. G. Smith, F. Wang, K. N. Wilkinson et al., "The phosphodiesterase PDE4B limits cAMP-associated PI3K/AKTdependent apoptosis in diffuse large B-cell lymphoma," Blood, vol. 105, no. 1, pp. 308-316, 2005.

[57] M. A. Shipp, K. N. Ross, P. Tamayo et al., "Diffuse large B-cell lymphoma outcome prediction by gene-expression profiling and supervised machine learning," Nature Medicine, vol. 8, no. 1, pp. 68-74, 2002.

[58] K. K. Hoyer, S. W. French, D. E. Turner et al., "Dysregulated TCL1 promotes multiple classes of mature B cell lymphoma," Proceedings of the National Academy of Sciences of the United States of America, vol. 99, no. 22, pp. 14392-14397, 2002.

[59] G. Lenz, G. W. Wright, N. C. T. Emre et al., "Molecular subtypes of diffuse large B-cell lymphoma arise by distinct genetic pathways," Proceedings of the National Academy of Sciences of the United States of America, vol. 105, no. 36, pp. 13520-13525, 2008.

[60] A. Navarro, S. Beà, V. Fernández et al., "MicroRNA expression, chromosomal alterations, and immunoglobulin variable heavy chain hypermutations in mantle cell lymphomas," Cancer Research, vol. 69, no. 17, pp. 7071-7078, 2009.

[61] A. V. Miletic, A. N. Anzelon-Mills, D. M. Mills et al., "Coordinate suppression of B cell lymphoma by PTEN and SHIP phosphatases," The Journal of Experimental Medicine, vol. 207, pp. 2407-2420, 2010.

[62] D. Iwakiri and K. Takada, "Phosphatidylinositol 3-kinase is a determinant of responsiveness to B cell antigen receptormediated epstein-barr virus activation," Journal of Immunology, vol. 172, no. 3, pp. 1561-1566, 2004.

[63] L. C. Platanias, "Map kinase signaling pathways and hematologic malignancies," Blood, vol. 101, no. 12, pp. 4667-4679, 2003.

[64] K. S. J. Elenitoba-Johnson, S. D. Jenson, R. T. Abbott et al., "Involvement of multiple signaling pathways in follicular lymphoma transformation: p38-mitogen-activated protein kinase as a target for therapy," Proceedings of the National 
Academy of Sciences of the United States of America, vol. 100, no. 12, pp. 7259-7264, 2003.

[65] A. Rinaldi, I. Kwee, M. Taborelli et al., "Genomic and expression profiling identifies the B-cell associated tyrosine kinase Syk as a possible therapeutic target in mantle cell lymphoma," British Journal of Haematology, vol. 132, no. 3, pp. 303-316, 2006.

[66] X. Huang, S. Wullschleger, M. Shpiro et al., "Important role of the LKB1-AMPK pathway in suppressing tumorigenesis in PTEN-deficient mice," Biochemical Journal, vol. 412, no. 2, pp. 211-221, 2008.

[67] K. J. Mavrakis, H. Zhu, R. L. A. Silva et al., "Tumorigenic activity and therapeutic inhibition of Rheb GTPase," Genes and Development, vol. 22, no. 16, pp. 2178-2188, 2008.

[68] D. D. Sarbassov, S. M. Ali, S. Sengupta et al., "Prolonged rapamycin treatment inhibits mTORC2 assembly and Akt/PKB," Molecular Cell, vol. 22, no. 2, pp. 159-168, 2006.

[69] D. A. Foster and A. Toschi, "Targeting mTOR with rapamycin: one dose does not fit all," Cell Cycle, vol. 8, no. 7, pp. 1026-1029, 2009.

[70] M. Gupta, S. M. Ansell, A. J. Novak, S. Kumar, S. H. Kaufmann, and T. E. Witzig, "Inhibition of histone deacetylase overcomes rapamycin-mediated resistance in diffuse large B-cell lymphoma by inhibiting Akt signaling through mTORC2," Blood, vol. 114, no. 14, pp. 2926-2935, 2009.

[71] K. Wanner, S. Hipp, M. Oelsner et al., "Mammalian target of rapamycin inhibition induces cell cycle arrest in diffuse large B cell lymphoma (DLBCL) cells and sensitises DLBCL cells to rituximab," British Journal of Haematology, vol. 134, no. 5, pp. 475-484, 2006.

[72] S. Hipp, I. Ringshausen, M. Oelsner, C. Bogner, C. Peschel, and T. Decker, "Inhibition of the mammalian target of rapamycin and the induction of cell cycle arrest in mantle cell lymphoma cells," Haematologica, vol. 90, no. 10, pp. 1433 1434, 2005.

[73] T. Peng, T. R. Golub, and D. M. Sabatini, "The immunosuppressant rapamycin mimics a starvation-like signal distinct from amino acid and glucose deprivation," Molecular and Cellular Biology, vol. 22, no. 15, pp. 5575-5584, 2002.

[74] J. LoPiccolo, G. M. Blumenthal, W. B. Bernstein, and P. A. Dennis, "Targeting the PI3K/Akt/mTOR pathway: effective combinations and clinical considerations," Drug Resistance Updates, vol. 11, no. 1-2, pp. 32-50, 2008.

[75] L. Bonapace, B. C. Bornhauser, M. Schmitz et al., "Induction of autophagy-dependent necroptosis is required for childhood acute lymphoblastic leukemia cells to overcome glucocorticoid resistance," Journal of Clinical Investigation, vol. 120, no. 4, pp. 1310-1323, 2010.

[76] H. Takeuchi, Y. Kondo, K. Fujiwara et al., "Synergistic augmentation of rapamycin-induced autophagy in malignant glioma cells by phosphatidylinositol 3-kinase/protein kinase B inhibitors," Cancer Research, vol. 65, no. 8, pp. 3336-3346, 2005.

[77] D. T. Teachey, S. A. Grupp, and V. I. Brown, "Mammalian target of rapamycin inhibitors and their potential role in therapy in leukaemia and other haematological malignancies," British Journal of Haematology, vol. 145, no. 5, pp. 569-580, 2009.

[78] R. Yuan, A. Kay, W. J. Berg, and D. Lebwohl, "Targeting tumorigenesis: development and use of mTOR inhibitors in cancer therapy," Journal of Hematology and Oncology, vol. 2, article 45, 2009.

[79] J. Tabernero, F. Rojo, E. Calvo et al., "Dose- and scheduledependent inhibition of the mammalian target of rapamycin pathway with everolimus: a phase I tumor pharmacodynamic study in patients with advanced solid tumors," Journal of Clinical Oncology, vol. 26, no. 10, pp. 1603-1610, 2008.

[80] Z. Zeng, D. D. Sarbassov, I. J. Samudio et al., "Rapamycin derivatives reduce $\mathrm{mTORC} 2$ signaling and inhibit AKT activation in AML," Blood, vol. 109, no. 8, pp. 3509-3512, 2007.

[81] L. Wang, W. Y. Shi, Z. Y. Wu et al., "Cytostatic and antiangiogenic effects of temsirolimus in refractory mantle cell lymphoma," Journal of Hematology \& Oncology, vol. 3, p. 30, 2010.

[82] V. Y. Yazbeck, D. Buglio, G. V. Georgakis et al., "Temsirolimus downregulates p 21 without altering cyclin D1 expression and induces autophagy and synergizes with vorinostat in mantle cell lymphoma," Experimental Hematology, vol. 36, no. 4, pp. 443-450, 2008

[83] M. Hidalgo, J. C. Buckner, C. Erlichman et al., "A phase I and pharmacokinetic study of temsirolimus (CCI-779) administered intravenously daily for 5 days every 2 weeks to patients with advanced cancer," Clinical Cancer Research, vol. 12, no. 19, pp. 5755-5763, 2006.

[84] E. Raymond, J. Alexandre, S. Faivre et al., "Safety and pharmacokinetics of escalated doses of weekly intravenous infusion of CCI-779, a novel mTOR inhibitor, in patients with cancer," Journal of Clinical Oncology, vol. 22, no. 12, pp. 2336-2347, 2004.

[85] A. O'Donnell, S. Faivre, H. A. Burris III et al., "Phase I pharmacokinetic and pharmacodynamic study of the oral mammalian target of rapamycin inhibitor everolimus in patients with advanced solid tumors," Journal of Clinical Oncology, vol. 26, no. 10, pp. 1588-1595, 2008.

[86] C. Tanaka, T. O’Reilly, J. M. Kovarik et al., "Identifying optimal biologic doses of everolimus (RAD001) in patients with cancer based on the modeling of preclinical and clinical pharmacokinetic and pharmacodynamic data," Journal of Clinical Oncology, vol. 26, no. 10, pp. 1596-1602, 2008.

[87] M. M. Mita, A. C. Mita, Q. S. Chu et al., "Phase I trial of the novel mammalian target of rapamycin inhibitor deforolimus (AP23573; MK-8669) administered intravenously daily for 5 days every 2 weeks to patients with advanced malignancies," Journal of Clinical Oncology, vol. 26, no. 3, pp. 361-367, 2008.

[88] G. J. Fetterly, M. M. Mita, C. D. Britten et al., "Tolcher AW Pharmacokinetics of oral deforolimus (AP23573, MK8669)," Journal of Clinical Oncology, vol. 26, Abstract 3509, 2008.

[89] E. Drakos, G. Z. Rassidakis, and L. J. Medeiros, "Mammalian target of rapamycin (mTOR) pathway signalling in lymphomas," Expert Reviews in Molecular Medicine, vol. 10, no. 4, article e4, pp. 1-21, 2008.

[90] E. S. Jaffe, "The 2008 WHO classification of lymphomas: implications for clinical practice and translational research," Hematology, pp. 523-531, 2009.

[91] J. E. Romaguera, "Mantle cell lymphoma: frontline and salvage therapy," Current Hematologic Malignancy Reports, vol. 3, no. 4, pp. 204-209, 2008.

[92] T. Haritunians, A. Mori, J. O’Kelly, Q. T. Luong, F. J. Giles, and H. P. Koeffler, "Antiproliferative activity of RAD001 (everolimus) as a single agent and combined with other agents in mantle cell lymphoma," Leukemia, vol. 21, no. 2, pp. 333-339, 2007.

[93] K. W. L. Yee, Z. Zeng, M. Konopleva et al., "Phase I/II study of the mammalian target of rapamycin inhibitor everolimus (RAD001) in patients with relapsed or refractory hematologic malignancies," Clinical Cancer Research, vol. 12, no. 17, pp. 5165-5173, 2006. 
[94] T. E. Witzig, S. M. Geyer, I. Ghobrial et al., "Phase II trial of single-agent temsirolimus (CCI-779) for relapsed mantle cell lymphoma," Journal of Clinical Oncology, vol. 23, no. 23, pp. 5347-5356, 2005.

[95] S. M. Ansell, D. J. Inwards, K. M. Rowland et al., "Lowdose, single-agent temsirolimus for relapsed mantle cell lymphoma: a phase 2 trial in the North Central Cancer Treatment Group," Cancer, vol. 113, no. 3, pp. 508-514, 2008.

[96] G. Hess, R. Herbrecht, J. Romaguera et al., "Phase III study to evaluate temsirolimus compared with investigator's choice therapy for the treatment of relapsed or refractory mantle cell lymphoma," Journal of Clinical Oncology, vol. 27, no. 23, pp. 3822-3829, 2009.

[97] R. Yuan, A. Kay, W. J. Berg, and D. Lebwohl, "Targeting tumorigenesis: development and use of mTOR inhibitors in cancer therapy," Journal of Hematology and Oncology, vol. 2, article 45, 2009.

[98] S. M. Ansell, H. Tang, P. J. Kurtin et al., "Temsirolimus and rituximab in patients with relapsed or refractory mantle cell lymphoma: a phase 2 study," The Lancet Oncology, vol. 12, pp. 361-368, 2011.

[99] T. E. Witzig, C. B. Reeder, B. R. Laplant et al., "A phase II trial of the oral mTOR inhibitor everolimus in relapsed aggressive lymphoma," Leukemia, vol. 25, pp. 341-347, 2011.

[100] D. A. Rizzieri, E. Feldman, J. F. Dipersio et al., "A phase 2 clinical trial of deforolimus (AP23573, MK-8669), a novel mammalian target of rapamycin inhibitor, in patients with relapsed or refractory hematologic malignancies," Clinical Cancer Research, vol. 14, no. 9, pp. 2756-2762, 2008.

[101] J. O. Armitage and D. D. Weisenburger, "New approach to classifying non-Hodgkin's lymphomas: clinical features of the major histologic subtypes. Non-Hodgkin's Lymphoma Classification Project," Journal of Clinical Oncology, vol. 16, pp. 2780-2795, 1998.

[102] S. Uddin, A. R. Hussain, A. K. Siraj et al., "Role of phosphatidylinositol 3'-kinase/AKT pathway in diffuse large B-cell lymphoma survival," Blood, vol. 108, no. 13, pp. 41784186, 2006.

[103] S. M. Smith, K. van Besien, T. Karrison et al., "Temsirolimus has activity in non-mantle cell non-Hodgkin's lymphoma subtypes: the University of Chicago phase II consortium," Journal of Clinical Oncology, vol. 28, pp. 4740-4746, 2010.

[104] D. C. Fingar, S. Salama, C. Tsou, ED. Harlow, and J. Blenis, "Mammalian cell size is controlled by mTOR and its downstream targets S6K1 and 4EBP1/eIF4E," Genes and Development, vol. 16, no. 12, pp. 1472-1487, 2002.

[105] J. Montagne, M. J. Stewart, H. Stocker, E. Hafen, S. C. Kozma, and G. Thomas, "Drosophila S6 kinase: a regulator of cell size," Science, vol. 285, no. 5436, pp. 2126-2129, 1999.

[106] H. Stocker and E. Hafen, "Genetic control of cell size," Current Opinion in Genetics and Development, vol. 10, no. 5, pp. 529-535, 2000.

[107] T. V. Isaacson, "Expression of mTOR pathway proteins in malignant lymphoma," Laboratory Investigation, vol. 246A, 2007.

[108] G. V. Georgakis, Y. Li, G. Z. Rassidakis, L. J. Medeiros, G. B. Mills, and A. Younes, "Inhibition of the phosphatidylinositol-3 kinase/Akt promotes G1 cell cycle arrest and apoptosis in Hodgkin lymphoma," British Journal of Haematology, vol. 132, no. 4, pp. 503-511, 2006.

[109] F. Jundt, N. Raetzel, C. Muller et al., "A rapamycin derivative (everolimus) controls proliferation through down-regulation of truncated CCAAT enhancer binding protein beta and NF-kappaB activity in Hodgkin and anaplastic large cell lymphomas," Blood, vol. 106, pp. 1801-1817, 2005.
[110] P. B. Johnston, D. J. Inwards, J. P. Colgan et al., "A Phase II trial of the oral mTOR inhibitor everolimus in relapsed Hodgkin lymphoma," American Journal of Hematology, vol. 85, no. 5, pp. 320-324, 2010.

[111] M. R. Janes and D. A. Fruman, "Targeting TOR dependence in cancer," Oncotarget, vol. 1, pp. 69-76, 2010.

[112] S. M. Maira, F. Stauffer, J. Brueggen et al., "Identification and characterization of NVP-BEZ235, a new orally available dual phosphatidylinositol 3-kinase/mammalian target of rapamycin inhibitor with potent in vivo antitumor activity," Molecular Cancer Therapeutics, vol. 7, no. 7, pp. 1851-1863, 2008.

[113] V. Serra, B. Markman, M. Scaltriti et al., "NVP-BEZ235, a dual PI3K/mTOR inhibitor, prevents PI3K signaling and inhibits the growth of cancer cells with activating PI3K mutations," Cancer Research, vol. 68, no. 19, pp. 8022-8030, 2008.

[114] K. Kojima, M. Shimanuki, M. Shikami et al., "The dual PI3 kinase/mTOR inhibitor PI-103 prevents p53 induction by Mdm2 inhibition but enhances p53-mediated mitochondrial apoptosis in p53 wild-type AML," Leukemia, vol. 22, no. 9, pp. 1728-1736, 2008.

[115] M. E. Feldman, B. Apsel, A. Uotila et al., "Active-site inhibitors of mTOR target rapamycin-resistant outputs of mTORC1 and mTORC2," PLoS Biology, vol. 7, no. 2, article e38, pp. 0371-0383, 2009.

[116] P. M. Bhende, S. I. Park, M. S. Lim, D. P. Dittmer, and B. Damania, "The dual PI3K/mTOR inhibitor, NVP-BEZ235, is efficacious against follicular lymphoma," Leukemia, vol. 24, pp. 1781-1784, 2010.

[117] J. M. García-Martínez, J. Moran, R. G. Clarke et al., "Ku0063794 is a specific inhibitor of the mammalian target of rapamycin (mTOR)," Biochemical Journal, vol. 421, no. 1, pp. 29-42, 2009.

[118] C. C. Thoreen, S. A. Kang, J. W. Chang et al., "An ATPcompetitive mammalian target of rapamycin inhibitor reveals rapamycin-resistant functions of mTORC1," Journal of Biological Chemistry, vol. 284, no. 12, pp. 8023-8032, 2009.

[119] K. Yu, L. Toral-Barza, C. Shi et al., "Biochemical, cellular, and in vivo activity of novel ATP-competitive and selective inhibitors of the mammalian target of rapamycin," Cancer Research, vol. 69, no. 15, pp. 6232-6240, 2009.

[120] M. R. Janes, J. J. Limon, L. So et al., "Effective and selective targeting of leukemia cells using a TORC1/2 kinase inhibitor," Nature Medicine, vol. 16, no. 2, pp. 205-213, 2010.

[121] C. M. Chresta, B. R. Davies, I. Hickson et al., "AZD-8055 is a potent, selective and orally bioavailable ATP-competitive mammalian target of rapamycin kinase inhibitor with in vitro and in vivo antitumor activity," Cancer Research, vol. 70, pp. 288-298, 2009.

[122] K. Yu, C. Shi, L. Toral-Barza et al., "Beyond rapalog therapy: preclinical pharmacology and antitumor activity of WYE-125132, an ATP-competitive and specific inhibitor of mTORC1 and mTORC2," Cancer Research, vol. 70, no. 2, pp. 621-631, 2010.

[123] R. J. Dowling, I. Topisirovic, T. Alain et al., "mTORC1mediated cell proliferation, but not cell growth, controlled by the 4E-BPs," Science, vol. 328, pp. 1172-1176, 2010.

[124] G. J. Brunn, J. Williams, C. Sabers, G. Wiederrecht, J. C. Lawrence Jr., and R. T. Abraham, "Direct inhibition of the signaling functions of the mammalian target of rapamycin by the phosphoinositide 3-kinase inhibitors, wortmannin and LY294002," EMBO Journal, vol. 15, no. 19, pp. 5256-5267, 1996. 
[125] F. Chiarini, C. Grimaldi, F. Ricci et al., "Activity of the novel dual phosphatidylinositol 3-kinase/mammalian target of rapamycin inhibitor NVP-BEZ235 against T-cell acute lymphoblastic leukemia," Cancer Research, vol. 70, pp. 8097$8107,2010$.

[126] T. C. Zhang, H. J. Chu, J. Q. Zhao, X. Y. Zhou, and D. R. Shi, "Study on PI3K inhibitor LY294002 for chemotherapeutic sensitization in diffuse large B cell lymphoma cell lines," Zhonghua Xue Ye Xue Za Zhi, vol. 31, pp. 671-674, 2010.

[127] A. C. Hsieh, M. Costa, O. Zollo et al., "Genetic dissection of the oncogenic mTOR pathway reveals druggable addiction to translational control via 4EBP-eIF4E," Cancer Cell, vol. 17, no. 3, pp. 249-261, 2010. 


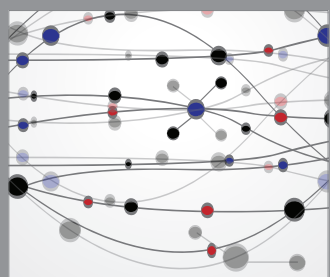

The Scientific World Journal
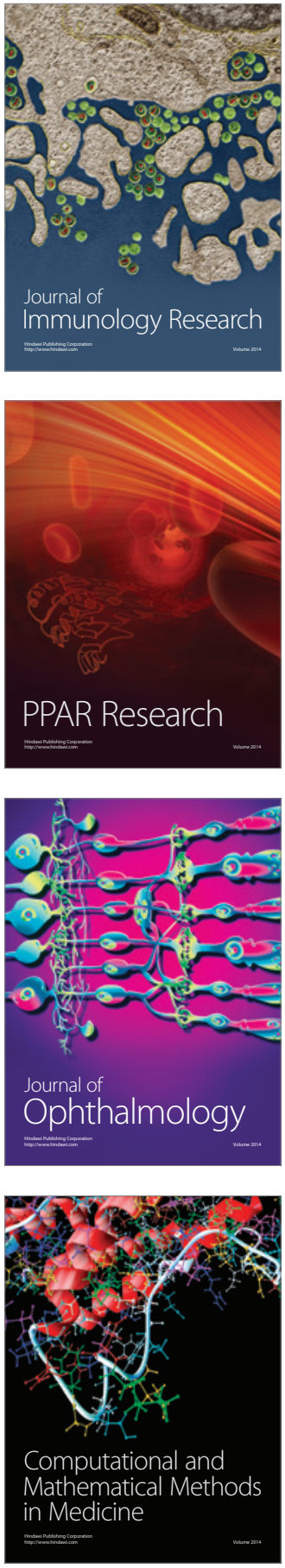

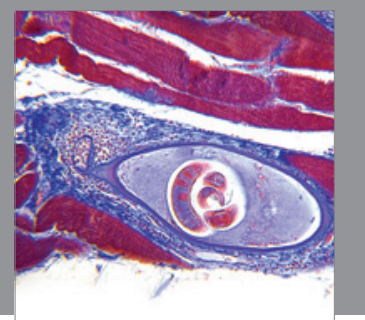

Gastroenterology

Research and Practice
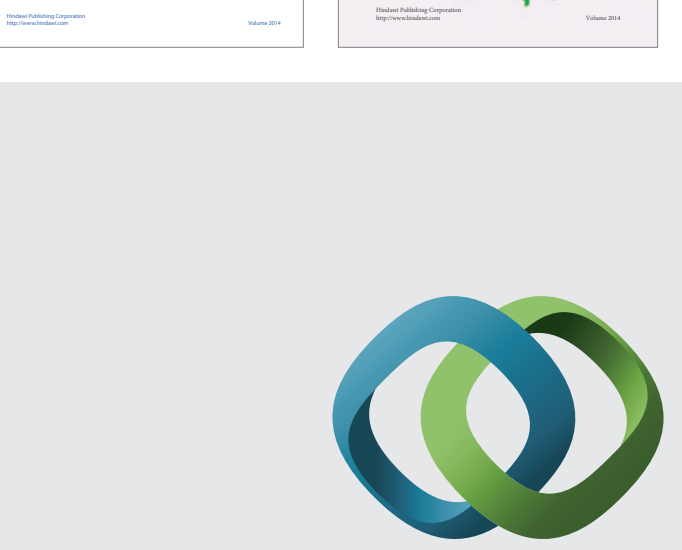

\section{Hindawi}

Submit your manuscripts at

http://www.hindawi.com
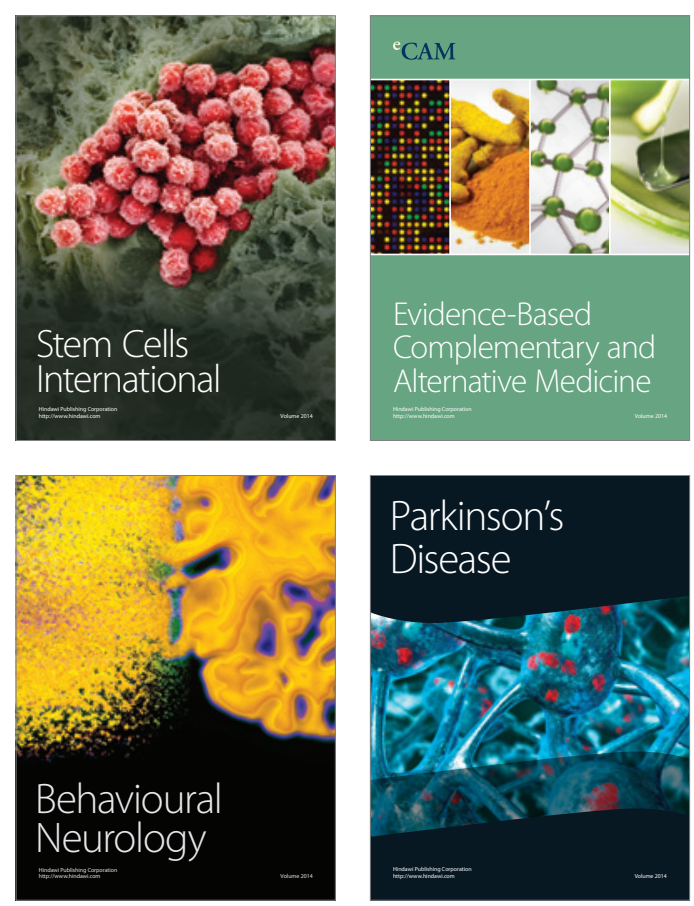

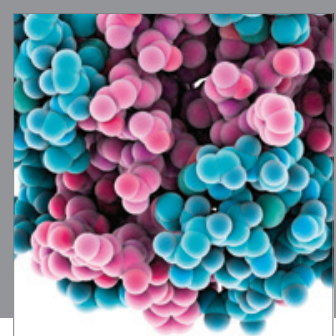

Journal of
Diabetes Research

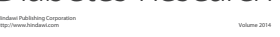

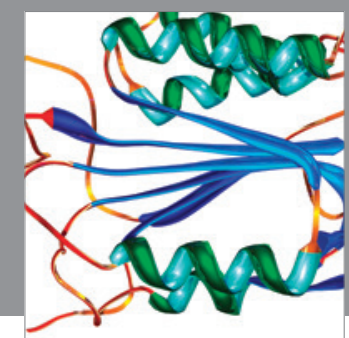

Disease Markers
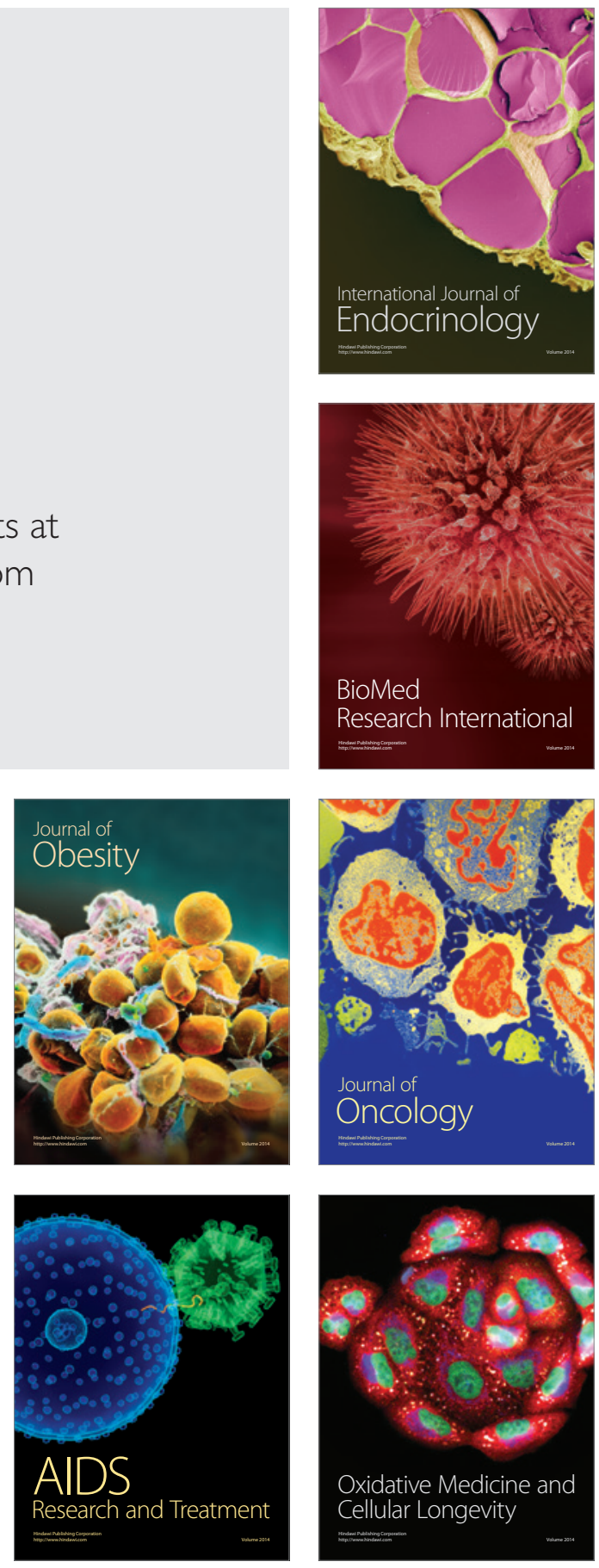